Research Paper

\title{
The Prognostic Value of Pretreatment Plasma Fibrinogen in Urological Cancers: A Systematic Review and Meta-analysis
}

\author{
Haifeng Song1,2,3* , Guanyu Kuang ${ }^{2,3^{*}}$, Zhenan Zhang1,2,3, Binglei Ma1,2,3, Jie Jin'1,2,3, Qian Zhang1,2,3凶 \\ 1. Department of Urology, Peking University First Hospital, Beijing 100034, China \\ 2. Institute of Urology, Peking University, Beijing 100034, China \\ 3. National Research Center for Genitourinary Oncology, Beijing 100034, China \\ *These authors contributed equally to this work.
}

$\triangle$ Corresponding author: Dr. Qian Zhang, Department of Urology, Peking University First Hospital, Institute of Urology, Peking University, National Research Center for Genitourinary Oncology, 8 Xishiku Street, Xicheng District, Beijing 100034, China. Email address: zhangqianbjmu@126.com; Phone: 0086-010-83572481.

(c) Ivyspring International Publisher. This is an open access article distributed under the terms of the Creative Commons Attribution (CC BY-NC) license (https://creativecommons.org/licenses/by-nc/4.0/). See http://ivyspring.com/terms for full terms and conditions.

Received: 2018.05.01; Accepted: 2018.10.21; Published: 2019.01.01

\begin{abstract}
Objective: Growing evidence suggests pretreatment fibrinogen can serve as a prognostic marker in various malignancies. However, there are contradictory results about the prognostic role of fibrinogen in urological cancers. We conducted a meta-analysis to evaluate the association between pretreatment plasma fibrinogen and survival outcomes in urological cancers.

Methods: After a systematic search of PubMed and Embase, we included 14 studies in our meta-analysis, and estimated hazard ratios (HRs) for overall survival (OS) and cancer-specific survival (CSS) using a fixed-effect model.

Results: Our results indicate that pretreatment plasma fibrinogen is a prognostic factor in urological cancers (OS: $\mathrm{HR}=2.21,95 \% \mathrm{Cl}=1.91-2.57, \mathrm{P}<0.001$, CSS: $\mathrm{HR}=2.67,95 \% \mathrm{Cl}=2.23-3.19, \mathrm{P}<0.001$ ). Elevated pretreatment plasma fibrinogen is associated with poorer survival in prostate cancer (OS: $\mathrm{HR}=2.26,95 \% \mathrm{Cl}=1.47-3.48, \mathrm{P}<0.001$; $\mathrm{CSS}: \mathrm{HR}=2.42,95 \% \mathrm{Cl}=1.44-4.07, \mathrm{P}=0.001$ ), renal cell carcinoma (OS: $\mathrm{HR}=2.13,95 \% \mathrm{Cl}=1.75-2.61, \mathrm{P}<0.001$; $\mathrm{CSS}$ : $\mathrm{HR}=2.99,95 \% \mathrm{Cl}=2.29-3.89, \mathrm{P}<0.001$ ) and upper tract urothelial carcinoma (OS: $\mathrm{HR}=2.34,95 \% \mathrm{Cl}=1.81-3.02, \mathrm{P}<0.001$; CSS: $\mathrm{HR}=2.43$, $95 \% \mathrm{Cl}=1.84-3.20, \mathrm{P}<0.001)$. Subgroup analyses showed that plasma fibrinogen has a more negative impact on survival in Caucasian patients (OS: $\mathrm{HR}=2.52,95 \% \mathrm{Cl}=1.95-3.25, \mathrm{P}<0.001$; CSS: $\mathrm{HR}=2.83$, $95 \% \mathrm{Cl}=1.92-4.17, \mathrm{P}<0.001$ ) than Asian patients (OS: $\mathrm{HR}=2.07,95 \% \mathrm{Cl}=1.73-2.49, \mathrm{P}<0.001$; CSS: $\mathrm{HR}=2.63,95 \% \mathrm{Cl}=2.14-3.22, \mathrm{P}<0.001)$. The prognostic value of fibrinogen is also consistent when stratified by different cut-off values.

Conclusions: These results show that high pretreatment plasma fibrinogen levels can predict poorer OS and CSS in patients with urological cancers.
\end{abstract}

Key words: fibrinogen, urological cancers, prognosis, biomarker, meta-analysis

\section{Introduction}

Hemostatic factors play important roles in cancer development, growth, and metastasis. Plasma fibrinogen is an acute phase glycoprotein associated with hemostasis maintenance and is a key factor in inflammation [1]. Fibrinogen is reportedly synthesized and overexpressed in human tumors [2], and plays an important role in tumor cell proliferation, invasion, and angiogenesis [3, 4]. Pretreatment fibrinogen levels can predict survival outcomes in various urological cancers, including 
renal cell carcinoma (RCC) $[5,6]$, prostate cancer (PCa) [7], upper tract urothelial carcinoma (UTUC) [8], and others [9]. However, the prognostic role of fibrinogen is still unclear. Du, et al. and Lee, et al. showed that high preoperative plasma fibrinogen levels predicted worse overall survival (OS) in RCC patients [6] [10], while Erdem, et al. found no relationship between plasma fibrinogen levels and OS in localized RCC patients [11]. Perisanidis, et al. performed a meta-analysis in solid tumors to assess the prognostic value of pretreatment fibrinogen, but their study focused on RCC and included only a small number of studies [12]. Another recent meta-analysis focused on the association between fibrinogen and RCC[13], PCa and UTUC were still not taken into account. Thus, the present meta-analysis included more cancer types and additional recent studies in evaluating the prognostic value of pretreatment plasma fibrinogen on survival outcomes in urological cancers.

\section{Materials and Methods}

Before starting our research, we registered our systematic review project at PROSPERO (International Prospective Register of Systemic Reviews, http://www.crd.york.ac.uk/prospero; registration code: CRD42016043821). We conducted this meta-analysis according to the Meta-analysis of Observational Studies in Epidemiology (MOOSE) criteria (Supplementary Material).

\section{Literature search}

We systematically searched PubMed and Embase to obtain all eligible clinical studies published before May 2017. There was no language restriction in our search. We used Mesh terms and keywords (fibrinogen, renal cell carcinoma, upper tract urothelial carcinoma, bladder cancer, prostate cancer, and urological cancer) to search for related articles in the databases (Supplementary Material). We also examined the references of relevant articles to retrieve potentially eligible studies. Two investigators (Haifeng Song and Guanyu Kuang) independently conducted the literature search.

\section{Inclusion and exclusion criteria}

Studies were included if they met all of the following criteria: 1) cohort studies on patients with urological tumors who were diagnosed pathologically; 2) survival outcomes included overall survival (OS) and/or cancer-specific survival (CSS); 3) results were expressed as hazard ratios (HRs) and corresponding 95\% confidence intervals (CIs) or P-values, or HRs could be calculated based on information provided in the article. Studies were excluded based on any of the following criteria: 1) review articles, case reports, laboratory articles, or letters; 2) papers lacked key information to calculate HRs; 3 ) if more than one study used the same patient cohort, only the most recent or complete study was selected.

\section{Data extraction and quality assessment}

Two reviewers independently extracted data from all eligible studies using a predesigned form. Extracted data included first author name, publication year, country, tumor site, sample size, patient age and gender, cut-off value, follow-up duration, outcome measures (OS, CSS, HRs, 95\%CI), and survival analysis (univariate/multivariate). If both univariate and multivariate analyses were conducted, we chose the multivariate analysis HRs, which accounted for confounding factors. We assessed study quality according to the Newcastle-Ottawa Scale (NOS). NOS includes three domains with eight items. Each item was awarded one or two stars. Studies with more than five stars were deemed good quality. Data extractions and quality assessments were performed independently by two investigators (Haifeng Song and Guanyu Kuang). Disagreements were resolved by a third reviewer (Binglei Ma) and group discussion.

\section{Statistical analysis}

The prognostic values of plasma fibrinogen levels in urological cancers were evaluated using HRs and 95\% CIs of CSS and OS, which we extracted directly from original articles. Cochran's Q-test and Higgins $\mathrm{I}^{2}$ statistics $\left(\mathrm{I}^{2}\right)$ were used to evaluate the heterogeneity of included studies. Heterogeneity was indicated by $\mathrm{I}^{2}>50 \%$ or $\mathrm{P}<0.05$. The fixed-effects model (Mantel-Haenszel method) was used to calculate pooled HRs if there was no heterogeneity. Otherwise, the random effect model was used. Subgroup analysis was conducted to identify the source of heterogeneity. Egger's and Begg's tests were performed to evaluate publication bias. All statistical analyses were performed using STATA version 14.0 (Stata Corporation, College Station, TX, USA).

\section{Results}

\section{Characteristics of included studies}

We identified 879 records by searching the PubMed and Embase databases. Two records were identified by examining article bibliographies. We excluded 96 duplicates. After screening titles and abstracts, 763 records were excluded and the remaining 22 were selected for full-text reading. Eight of these 22 articles were excluded: two studies were not prognosis-related, four had no OS or CSS as final outcome, and two included data that overlapped with 
other studies. In total, 14 studies met our eligibility criteria and were included in the final meta-analysis (Fig 1, Table 1).

The included studies had 6740 total cases from six countries (China, Japan, Korea, Germany, Austria, and Turkey). Two studies explored the prognostic value of fibrinogen in PCa (including 558 patients), eight in RCC (including 5132 patients), and four in UTUC (including 1050 patients). There were no studies of bladder cancer. As for survival outcomes, 11 studies evaluated the prognostic value of fibrinogen in predicting OS, and 12 evaluated CSS. All included studies had NOS scores $>5$ and were considered good quality.

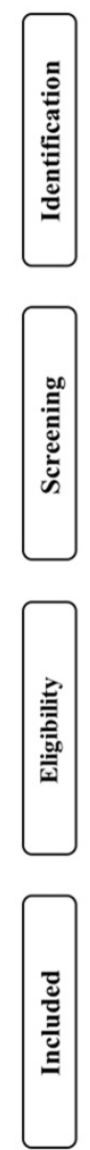

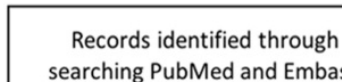

searching PubMed and Embase $(n=879)$
Additional records identified through reading references of related articles $(n=2)$

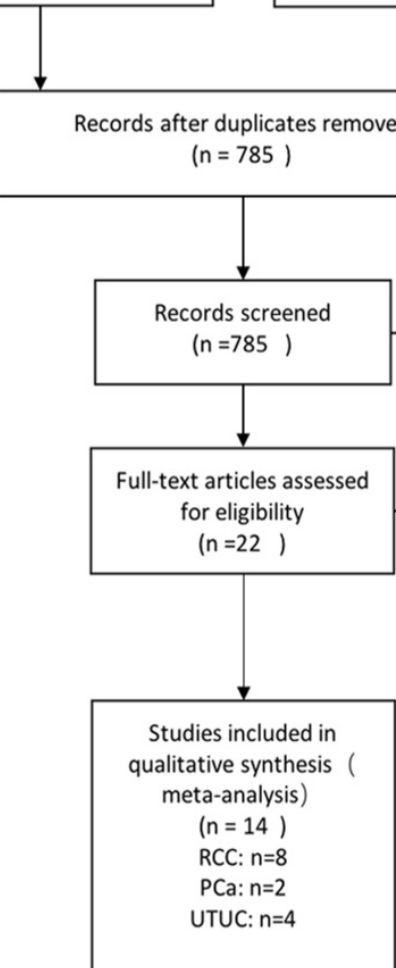

Figure 1. Flow diagram of the study selection process.

Table 1. Characteristics of all 14 studies included in the meta-analysis

\begin{tabular}{|c|c|c|c|c|c|c|c|c|c|c|c|}
\hline Author & Year & Country & $\begin{array}{l}\text { Tumor } \\
\text { site }\end{array}$ & $\begin{array}{l}\mathrm{N} \text { of } \\
\text { patients }\end{array}$ & Age (years) & Gender (M/F) & $\begin{array}{l}\text { Cut-off value } \\
(\mathrm{mg} / \mathrm{dL})\end{array}$ & Follow-up (Months) & $\begin{array}{l}\text { HR provided } \\
\text { from }\end{array}$ & Outcome & $\begin{array}{l}\text { NOS } \\
\text { score }\end{array}$ \\
\hline Thurner & 2015 & Austria[7] & $\mathrm{PCa}$ & 268 & Mean: $66.9 \pm 7.5$ & $268 / 0$ & 530 & $88(83.3-92.7)$ & MV/UV & CSS,OS,DFS & 8 岤 \\
\hline Wang & 2016 & China[34] & $\mathrm{PCa}$ & 290 & Mean: 75 (67-79) & $290 / 0$ & 322.5 & $37(24.0-50.3)$ & $\mathrm{MV} / \mathrm{UV}$ & CSS,OS,PFS & 6it \\
\hline $\mathrm{Du}$ & 2013 & China[6] & RCC & 286 & $\begin{array}{l}\text { Median: } 55.72 \\
(28-77)\end{array}$ & $185 / 101$ & $300 / 400$ & $\begin{array}{l}\text { died: } 34.6 \text { survivors: } \\
94.5\end{array}$ & $\mathrm{MV} / \mathrm{UV}$ & OS,DFS & 7约 \\
\hline Pichler & 2013 & Austria[35] & $\mathrm{RCC}$ & 994 & Mean: $63.2 \pm 11.9$ & $599 / 395$ & 466 & $48.1(0-132)$ & $\mathrm{MV} / \mathrm{UV}$ & CSS,OS & 7 论 \\
\hline Erdem & 2014 & Turkey[11] & RCC & 156 & Mean: $58.66 \pm 11.31$ & $91 / 37$ & 343 & $36.5(1-88)$ & $\mathrm{MV} / \mathrm{UV}$ & CSS,OS,DFS & 8场 \\
\hline Niedworok & 2015 & Germany[36] & RCC & 98 & Mean: 64.6(18-88) & $61 / 37$ & 281 & $36(20-122)$ & UV & OS,DFS & 6论 \\
\hline Sasaki & 2015 & Japan[37] & $\mathrm{RCC}$ & 126 & Median: 67(37-86) & $84 / 42$ & 399 & $30.8(2-135)$ & $\mathrm{MV} / \mathrm{UV}$ & OS & 7论 \\
\hline Lee & 2016 & Korea[10] & RCC & 1511 & Median: 57.6(19-86) & $1077 / 434$ & 328 & $36(24-57)$ & $\mathrm{MV} / \mathrm{UV}$ & CSS,OS,PFS & 7场 \\
\hline Obata & 2016 & Japan[38] & RCC & 601 & Median 58(50-67) & $467 / 134$ & 420 & 74(47-107) & $\mathrm{MV} / \mathrm{UV}$ & CSS,DFS & 8 论 \\
\hline Peng & 2017 & China[39] & RCC & 1360 & Median 55(46-65) & $952 / 408$ & 387 & $67(36-74)$ & $\mathrm{MV} / \mathrm{UV}$ & CSS,PFS & 7论 \\
\hline Pichler & 2014 & Austria[40] & UTUC & 167 & Mean: $69.3 \pm 10.3$ & $122 / 80$ & 370 & 28 & $\mathrm{MV} / \mathrm{UV}$ & CSS,OS & 8场 \\
\hline Tanaka & 2013 & Japan[8] & UTUC & 218 & Mean: 69(38-92) & $160 / 58$ & 450 & $38(3-187)$ & $\mathrm{MV} / \mathrm{UV}$ & CSS & 8 访 \\
\hline Zhang & 2016 & China[41] & UTUC & 184 & Median: 70(61-75) & $84 / 100$ & 354 & $78(34-92)$ & $\mathrm{MV} / \mathrm{UV}$ & CSS,OS & 8访 \\
\hline Huang & 2016 & China[42] & UTUC & 481 & Mean: $65.8 \pm 11.1$ & $311 / 170$ & 422 & $40(24-64)$ & $\mathrm{MV} / \mathrm{UV}$ & CSS,OS & 8 场 \\
\hline
\end{tabular}

PCa: prostate cancer, RCC: renal cell carcinoma, UTUC: upper tract urothelial carcinoma, MV: multivariate, UV: univariate, OS: overall survival, CSS: cancer-specific survival, DFS: disease-free survival, PFS: progression-free survival 


\section{Overall survival}

High pretreatment plasma fibrinogen level was associated with worse OS in urological cancers (fixed effect model, pooled $\mathrm{HR}=2.21$, 95\% CI=1.91-2.57; $\mathrm{P}<0.001$ ) (Fig 2A, Table 2). No heterogeneity across studies was found $\left(\mathrm{I}^{2}=0 \%, \mathrm{P}_{\mathrm{H}}=0.723\right)$. Subgroup analysis by tumor type showed that high pretreatment plasma fibrinogen levels were associated with a worse OS in PCa (fixed effect model, pooled $\mathrm{HR}=2.26,95 \% \mathrm{CI}=1.47-3.48, \mathrm{P}<0.001)$, RCC (fixed effect model, pooled $\mathrm{HR}=2.13$, 95\% $\mathrm{CI}=1.75-2.61, \mathrm{P}<0.001$ ) and UTUC (fixed effect model, pooled $\mathrm{HR}=2.34,95 \% \mathrm{CI}=1.81-3.02, \mathrm{P}<0.001)$ (Fig 2B). In subgroup analyses by race, high pretreatment fibrinogen levels predicted worse OS in both Asian (fixed effect model, pooled $\mathrm{HR}=2.07$, 95\% $\mathrm{CI}=1.73-2.49, \mathrm{P}<0.001$ ) and Caucasian (random effect model, pooled $\mathrm{HR}=2.52,95 \% \mathrm{CI}=1.93-3.25, \mathrm{P}<0.001$ ) populations (Fig 2C). Statistically significant pooled HR values were consistently calculated in subgroup analyses when stratified by different cutoff points. (Table 2).

Table 2. HR values for OS according to subgroup analysis

\begin{tabular}{|c|c|c|c|c|c|c|}
\hline \multirow[t]{2}{*}{ Subgroup } & \multirow{2}{*}{$\begin{array}{l}\text { No. } \\
\text { studies }\end{array}$} & \multirow{2}{*}{$\begin{array}{l}\text { No. } \\
\text { patients }\end{array}$} & \multicolumn{2}{|c|}{ Fixed-effects model } & \multicolumn{2}{|c|}{ Heterogeneity } \\
\hline & & & HR (95\% CI) & $P$-value & $\mathrm{I}^{2}(\%)$ & $P_{H \text {-value }}$ \\
\hline \multicolumn{7}{|l|}{ Tumor } \\
\hline \multicolumn{7}{|l|}{ Site } \\
\hline$P C a$ & 2 & 558 & $2.26(1.47-3.48)$ & $<0.001$ & 2.7 & 0.311 \\
\hline$R C C$ & 6 & 3171 & $2.13(1.75-2.61)$ & $<0.001$ & 5.1 & 0.384 \\
\hline UTUC & 3 & 832 & 2.34 (1.81-3.02) & $<0.001$ & 0 & 0.811 \\
\hline \multicolumn{7}{|l|}{ Ethnicity } \\
\hline Asian & 6 & 2878 & 2.07 (1.73-2.49) & $<0.001$ & 0 & 0.490 \\
\hline Caucasian & 5 & 1683 & $2.52(1.95-3.25)$ & $<0.001$ & 0 & 0.893 \\
\hline \multicolumn{7}{|l|}{$\begin{array}{l}\text { Cut-off } \\
\text { value }\end{array}$} \\
\hline$<350 m g / d l$ & 5 & 2055 & $1.91(1.52-2.40)$ & $<0.001$ & 0 & 0.858 \\
\hline$\geq 350 \mathrm{mg} / \mathrm{dl}$ & 6 & 2506 & $2.46(2.03-2.98)$ & $<0.001$ & 0 & 0.707 \\
\hline Overall & 11 & 4561 & $2.21(1.91-2.57)$ & $<0.001$ & 0 & 0.723 \\
\hline
\end{tabular}

OS: overall survival, $\mathrm{HR}$ : hazard ratio, $\mathrm{CI}$ : confidence interval, $\mathrm{PH}$ : $\mathrm{P}$ for heterogeneity, PCa: prostate cancer, RCC: renal cell carcinoma, UTUC: upper tract urothelial carcinoma.

\section{Cancer-specific survival}

Elevated pretreatment fibrinogen was associated with worse CSS in urological cancers (fixed effect model, pooled $\mathrm{HR}=2.67,95 \% \mathrm{CI}=2.23-3.19, \mathrm{P}<0.001$ ) (Fig 3, Table 3). No heterogeneity was observed among studies $\left(\mathrm{I}^{2}=0 \%, \mathrm{P}_{\mathrm{H}}=0.888\right)$. Subgroup analyses by tumor type showed that high pretreatment fibrinogen levels were associated with reduced CSS in PCa (fixed effect model, pooled $\mathrm{HR}=2.42$, 95\% $\mathrm{CI}=1.44-4.07, \mathrm{P}=0.001$ ), RCC (fixed effect model, pooled $\mathrm{HR}=2.99,95 \% \mathrm{CI}=2.29-3.89, \mathrm{P}<0.001)$ and UTUC (fixed effect model, pooled $\mathrm{HR}=2.43$, 95\% $\mathrm{CI}=1.84-3.20, \mathrm{P}<0.001$ ) patients (Fig 3B, Table 3). High pretreatment plasma fibrinogen level was also associated with worse CSS in Asian (fixed effect model, pooled $\mathrm{HR}=2.63,95 \% \mathrm{CI}=2.14-3.22, \mathrm{P}<0.001$ ) and Caucasian (fixed effect model, pooled $H R=2.83$, 95\% CI=1.92-4.17, $\mathrm{P}<0.001)$ populations. This effect was greater in Caucasian than Asian patients (Fig 3C, Table 3). Different cut-off points both showed prognostic value of plasma fibrinogen for CSS.

Table 3. HR values for CSS according to subgroup analyses.

\begin{tabular}{|c|c|c|c|c|c|c|}
\hline \multirow[t]{2}{*}{ Subgroup } & \multirow{2}{*}{$\begin{array}{l}\text { No. } \\
\text { studies }\end{array}$} & \multirow{2}{*}{ No. patients } & \multicolumn{2}{|c|}{ Fixed-effects model } & \multicolumn{2}{|c|}{ Heterogeneity } \\
\hline & & & HR $(95 \%$ CI) & $P$-value & $\mathrm{I}^{2}(\%)$ & $P_{H \text {-value }}$ \\
\hline \multicolumn{7}{|l|}{ Tumor Site } \\
\hline$P C a$ & 2 & 558 & $2.42(1.44-4.07)$ & 0.001 & 0 & 0.425 \\
\hline$R C C$ & 6 & 4720 & $2.99(2.29-3.89)$ & $<0.001$ & 0 & 0.716 \\
\hline UTUC & 4 & 1050 & $2.43(1.84-3.20)$ & $<0.001$ & 0 & 0.807 \\
\hline \multicolumn{7}{|l|}{ Ethnicity } \\
\hline Asian & 7 & 4645 & $2.63(2.14-3.22)$ & $<0.001$ & 0 & 0.600 \\
\hline Caucasian & 5 & 1683 & 2.83 (1.92-4.17) & $<0.001$ & 0 & 0.894 \\
\hline \multicolumn{7}{|c|}{ Cut-off value } \\
\hline$<350 \mathrm{mg} / \mathrm{dl}$ & 4 & 2055 & $2.65(1.74-4.03)$ & $<0.001$ & 0 & 0.743 \\
\hline$\geq 350 \mathrm{mg} / \mathrm{dl}$ & 8 & 4273 & $2.67(2.19-3.26)$ & $<0.001$ & 0 & 0.716 \\
\hline Overall & 12 & 6328 & $2.67(2.23-3.19)$ & $<0.001$ & 0 & 0.888 \\
\hline
\end{tabular}

CSS: cancer-specific survival, HR: hazard ratio, CI: confidence interval, $P_{H}: \mathrm{P}$ for heterogeneity, PCa: prostate cancer, RCC: renal cell carcinoma, UTUC: upper tract urothelial carcinoma.

\section{Publication bias}

Publication bias in the included investigations was assessed using Begg's test and Egger's linear regression test. In Begg's test, $\mathrm{P}=0.213$ for OS and $\mathrm{P}=0.064$ for CSS. In Egger's test, $\mathrm{P}=0.119$ for OS and $\mathrm{P}=0.111$ for CSS. Thus, no significant publication bias was observed in our meta-analysis. The Egger's linear regression graph is shown in Figure 4.

\section{Discussion}

Our meta-analysis included 6740 patients in 14 eligible studies of good quality as assessed by the NOS score system. Our findings suggest that pretreatment plasma fibrinogen levels can be used to predict survival outcomes in urological cancers. High pretreatment plasma fibrinogen levels predicted shorter OS and CSS in patients with RCC, PCa, or UTUC. In subgroup analyses, RCC had the highest HR value for CSS, while UTUC had the highest HR value for OS, indicating that pretreatment plasma fibrinogen had the best predictive value for CSS in RCC and OS in UTUC. The prognostic value of pretreatment fibrinogen was confirmed in all three urological cancer types despite different effect sizes. When stratified by race, pretreatment plasma fibrinogen had stronger predictive values for both OS and CSS in Caucasian patients than Asians.

While no bladder cancer studies met our inclusion criteria, the association between pretreatment plasma fibrinogen level and bladder cancer clinicopathological characteristics has been assessed. Liu, et al. reported that advanced stage (high grade or muscle-invasive) bladder urothelial 
carcinoma patients had higher plasma fibrinogen levels than those with early-stage (low grade or non-muscle-invasive) disease, and high plasma fibrinogen level $(>3.04 \mathrm{~g} / \mathrm{L})$ was identified as an independent predictor of advanced-stage disease [14].
Another study also showed that fibrinogen level (cut-off value $3.17 \mathrm{~g} / \mathrm{L}$ ) could aid in distinguishing between muscle-invasive and non-muscle-invasive bladder cancer (sensitivity $58 \%$, specificity $58 \%$, AUC 0.6) [15].

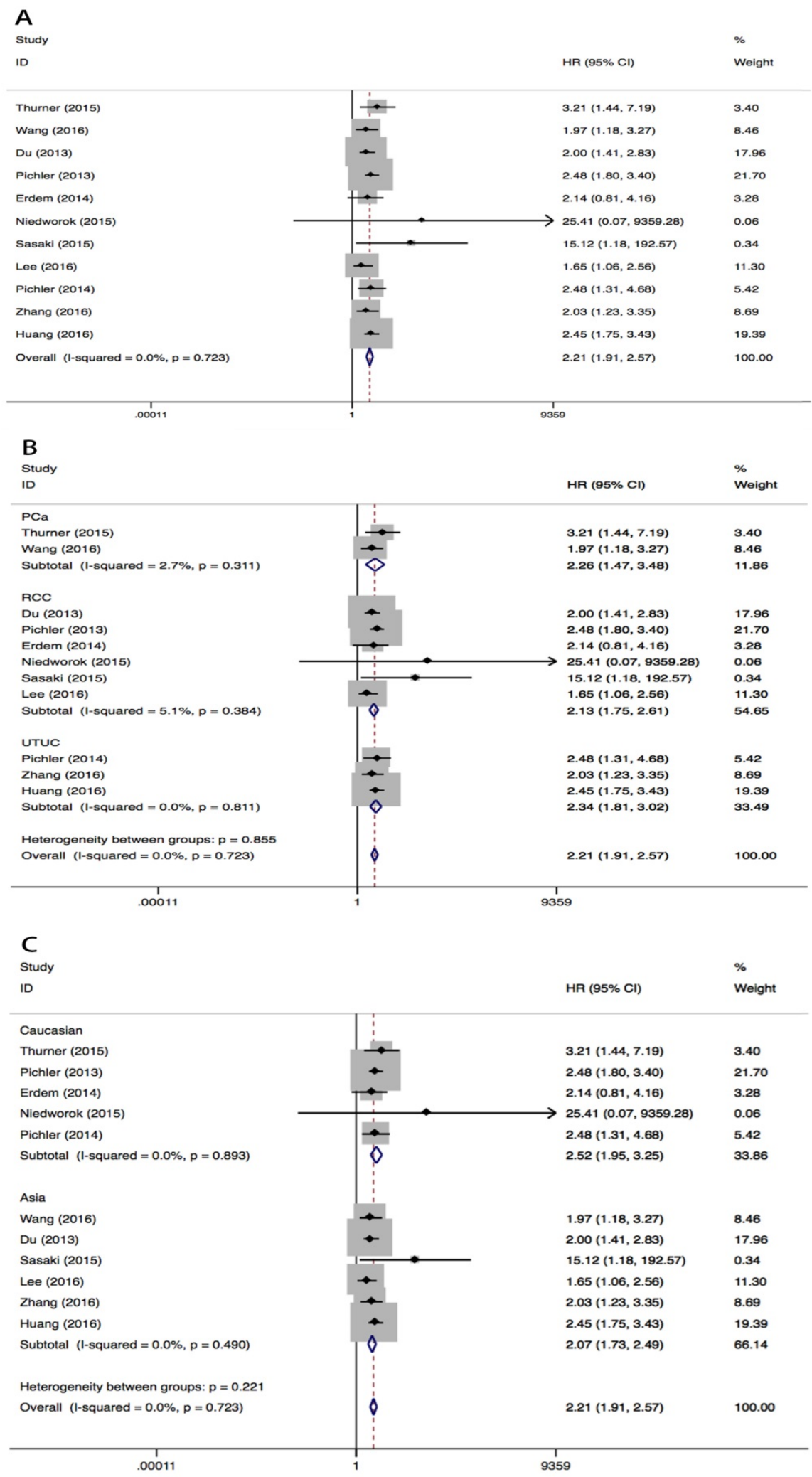

Figure 2. Meta-analysis of the association between pretreatment plasma fibrinogen and OS in urological cancers. Forest plot of studies evaluating pooled HR for OS in urological cancers $\mathbf{A}$. Forest plots of subgroup analyses by cancer type $\mathbf{B}$. and race $\mathbf{C}$. for $\mathrm{OS}$. 


\section{A}

$\begin{array}{llll}\text { Study } & & & \% \\ \text { Weight }\end{array}$

B

\begin{tabular}{|c|c|c|c|}
\hline \multicolumn{2}{|l|}{$\begin{array}{l}\text { Study } \\
\text { ID }\end{array}$} & \multirow[t]{2}{*}{$\mathrm{HR}(95 \% \mathrm{Cl})$} & \multirow[t]{2}{*}{$\begin{array}{l}\% \\
\text { Weight }\end{array}$} \\
\hline $\mathrm{PCa}$ & & & \\
\hline Thurner (2015) & Lـ & $3.96(1.06,14.87)$ & 1.85 \\
\hline Wang (2016) & $\rightarrow$ & $2.21(1.25,3.89)$ & 10.06 \\
\hline Subtotal (I-squared $=0.0 \%, p=0.425$ ) & $\diamond$ & $2.42(1.44,4.07)$ & 11.92 \\
\hline \multicolumn{4}{|l|}{$\mathrm{RCC}$} \\
\hline Pichler (2013) & $\rightarrow$ & $2.47(1.49,4.11)$ & 12.57 \\
\hline Erdem (2014) & $\rightarrow$ & $3.89(1.13,13.40)$ & 2.12 \\
\hline Niedworok (2015) & & $25.57(0.00,19890.89)$ & 0.05 \\
\hline Lee (2016) & $\rightarrow$ & $3.07(1.48,6.37)$ & 6.05 \\
\hline Obata (2016) & $\rightarrow$ & $5.14(2.33,11.40)$ & 5.13 \\
\hline Peng (2017) & $\sim$ & $2.81(1.88,4.19)$ & 20.06 \\
\hline Subtotal ( 1 -squared $=0.0 \%, p=0.716$ ) & & $2.99(2.29,3.89)$ & 45.98 \\
\hline \multicolumn{4}{|l|}{ UTUC } \\
\hline Pichler (2014) & $\rightarrow$ & $3.00(1.32,6.80)$ & 4.81 \\
\hline Tanaka (2013) & $\mid$ & $2.41(1.20,4.85)$ & 6.63 \\
\hline Zhang (2016) & $\rightarrow$ & $1.89(1.02,3.49)$ & 8.54 \\
\hline Huang (2016) & 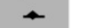 & $2.56(1.75,3.76)$ & 22.12 \\
\hline Subtotal $(1$-squared $=0.0 \%, p=0.807$ ) & 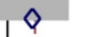 & $2.43(1.84,3.20)$ & 42.10 \\
\hline \multicolumn{4}{|l|}{ Heterogeneity between groups: $p=0.529$} \\
\hline Overall (I-squared $=0.0 \%, p=0.888$ ) & $\theta$ & $2.67(2.23,3.19)$ & 100.00 \\
\hline $5.0 \mathrm{e}-05$ & 1 & & \\
\hline
\end{tabular}

C

Study

ID

19891 

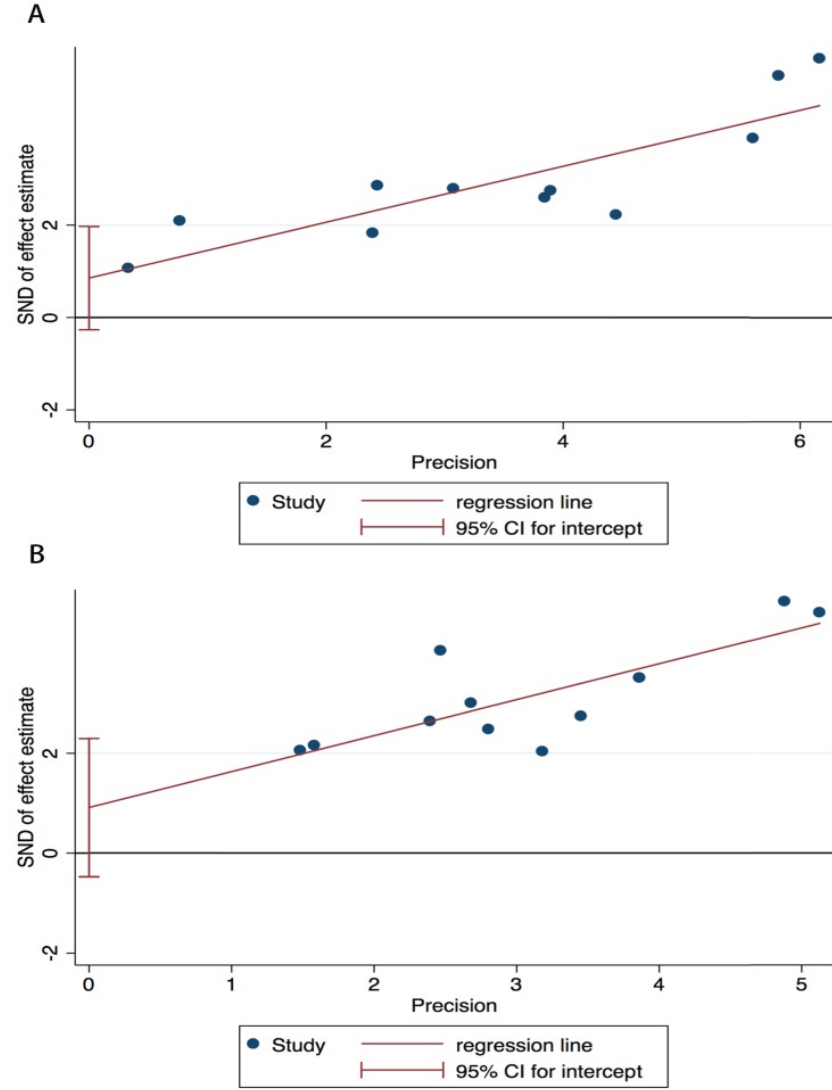

Figure 4. Egger's linear regression test. Egger's publication bias plots for OS A. and CSS B.

Negative associations between fibrinogen and tumor prognosis have been reported in multiple cancers, including lung [16], ovarian [17], cervical [18], hepatocellular [19], pancreatic [20], and colorectal cancer [21, 22]. However, the underlying biological mechanisms describing this relationship have not been fully elucidated. Fibrinogen appears to promote tumor proliferation, progression, and metastasis, and can be endogenously synthesized and secreted by cancer cells [2, 23]. Fibrinogen can stimulate cancer cell proliferation and angiogenesis by binding to transforming growth factor- $\beta$ (TGF- $\beta$ ), vascular growth factor (VEGF), fibroblast growth factor-2 (FGF-2), and platelet-derived growth factor (PDGF) [2, 24-26]. Fibrinogen is also a critical determinant of tumor growth with plasminogen in the tumor microenvironment [27] and can increase the metastatic potential of malignant tumors. Joseph, et al. suggested that fibrinogen deficiency reduced the incidence of spontaneous metastasis in aggressive tumors via both hematogenous and lymphatic routes [28]. Another study indicated that formation of platelet-fibrin-tumor cell aggregates is related to tumor cell endothelial adhesion and metastatic potential, and that fibrinogen may facilitate metastasis by enhancing the sustained adherence and survival of circulating tumor cell emboli in the vasculature of target organs [29]. In addition, fibrinogen may protect tumor cells from natural killer cell cytotoxicity because of their strong adhesion to tumor cells, which facilitated the immuno-escape and accelerated the metastasis of tumor cells [30].

Despite advances in anti-cancer therapies, some patients still experience poor clinical outcomes due to low objective response rates, tumor local recurrence, and distal metastasis. Novel biomarkers are needed to identify these patients. Studies showed some inflammation response biomarkers, such as C-reactive protein, neutrophil-to-lymphocyte ratio (NLR), platelet-to-lymphocyte ratio (PLR), and lymphocyte-to-monocyte ratio (LMR), were prognostic indicators of solid tumor outcomes [31, 32]. Plasma fibrinogen is associated with hemostasis maintenance and is a key factor in inflammation. Based on previous studies, our analysis revealed that plasma fibrinogen is a prognostic biomarker that could help identify high-risk urological cancer patients before treatment. Early identification of these patients and appropriate therapeutic decision-making could improve survival outcomes. The use of anticoagulants could diminish the risk of tumor thrombosis and hematogenous metastasis in patients with elevated plasma fibrinogen. Recombinant desulfatohirudin, a highly specific thrombin inhibitor, suppressed tumor metastasis in an animal model [33].

To our knowledge, this is the first meta-analysis to comprehensively assess the prognostic value of plasma fibrinogen in urological cancers. We found no significant heterogeneity or publication bias in our analysis. However, our study had certain limitations. First, the study by Niedworok, et al. [36] lacked multivariate analyses, so we used HRs from univariate analyses to calculate the pooled HR. Univariate analysis may overestimate effect sizes because of confounder bias. However, our meta-analysis did not show any notable difference in the pooled estimation when we excluded this study. Second, we estimated OS and CSS, but did not assess other survival outcomes, such as disease-free survival and progression-free survival. This was primarily due to a lack of data in the included articles. Third, our analysis included a small number of studies, and some cancer types, such as bladder cancer, were not included in the final analysis. Finally, because our meta-analysis was based on observational studies, we could not draw robust conclusions about how plasma fibrinogen level changes influence survival outcomes. Only the association between pretreatment plasma fibrinogen level and poor survival outcome could be deduced.

In conclusion, our meta-analysis was based on present studies and it revealed that high pretreatment 
plasma fibrinogen levels can predict worse OS and CSS in urological cancer patients. While further clinical studies are needed, our results suggest that pretreatment plasma fibrinogen might be an effective prognostic biomarker for such patients and could potentially influence decision-making during treatment.

\section{Abbreviations}

HRs: hazard ratios; OS: overall survival; CSS: cancer-specific survival; $\mathrm{CI}$ : confidence interval; I2: Higgins $\mathrm{I}^{2}$ statistics; $\mathrm{P}_{\mathrm{H}}$ : $\mathrm{P}$ for heterogeneity; PCa: prostate cancer; RCC: renal cell carcinoma; UTUC: upper tract urothelial carcinoma; NOS: The Newcastle-Ottawa Scale; TGF- $\beta$ : transforming growth factor- $\beta$; VEGF: vascular growth factor; FGF-2: fibroblast growth factor-2; PDGF: platelet-derived growth factor.

\section{Supplementary Material}

MOOSE Checklist, and Search Strategy.

http://www.jcancer.org/v10p0479s1.pdf

\section{Acknowledgements}

Haifeng Song and Qian Zhang conceived and designed the study, Haifeng Song, Guanyu Kuang, Zhenan Zhang and Binglei Ma participated in selecting study, extracting data, performing the statistical analysis, Haifeng Song and Guanyu Kuang drafted the manuscript. Qian Zhang and Jie Jin have been involved in revising the manuscript critically for important intellectual content. All authors read and approved the final manuscript.

\section{Competing Interests}

The authors have declared that no competing interest exists.

\section{References}

1. Hoppe B. Fibrinogen and factor XIII at the intersection of coagulation, fibrinolysis and inflammation. Thromb Haemost. 2014; 112: 649-58.

2. Sahni A, Simpson-haidaris PJ, Sahni SK, Vaday GG, Francis CW. Fibrinogen synthesized by cancer cells augments the proliferative effect of fibroblast growth factor-2 (FGF-2). Journal of Thrombosis and Haemostasis. 2008; 6: 176-83.

3. Steinbrecher KA, Horowitz NA, Blevins EA, Barney KA, Shaw MA, Harmel-Laws E, Finkelman FD, Flick MJ, Pinkerton MD, Talmage KE, Kombrinck KW, Witte DP, Palumbo JS. Colitis-Associated Cancer Is Dependent on the Interplay between the Hemostatic and Inflammatory Systems and Supported by Integrin $\alpha_{\mathrm{M}} \beta_{2}$ Engagement of Fibrinogen. Cancer Research. 2010; 70: 2634-43.

4. Shu YJ, Weng H, Bao RF, Wu XS, Ding Q, Cao Y, Wang XA, Zhang F, Xiang SS, Li HF, Li ML, Mu JS, Wu WG, et al. Clinical and prognostic significance of preoperative plasma hyperfibrinogenemia in gallbladder cancer patients following surgical resection: a retrospective and in vitro study. BMC Cancer. 2014; 14: 566 .

5. Bezan A, Hutterer GC, Stoeckigt C, Chromecki TF, Samonigg H, Stojakovic T, Pummer K, Zigeuner R, Pichler M. High pre-operative plasma fibrinogen levels represent a negative prognostic factor regarding cancer-specific, metastasis-free and overall survival in renal cell carcinoma. Memo-Magazine of European Medical Oncology. 2014; 7: 31.

6. Du J, Zheng JH, Chen XS, Yang Q, Zhang YH, Zhou L, Yao X. High preoperative plasma fibrinogen is an independent predictor of distant metastasis and poor prognosis in renal cell carcinoma. International Journal of Clinical Oncology. 2013; 18: 517-23.

7. Thurner EM, Krenn-Pilko S, Langsenlehner U, Stojakovic T, Pichler M, Gerger A, Kapp KS, Langsenlehner T. The association of an elevated plasma fibrinogen level with cancer-specific and overall survival in prostate cancer patients. World J Urol. 2015; 33: 1467-73.

8. Tanaka N, Kikuchi E, Matsumoto K, Hayakawa N, Ide H, Miyajima A, Nakamura S, Oya M. Prognostic value of plasma fibrinogen levels in patients with localized upper tract urothelial carcinoma. BJU International. 2013; 111: 857-64.

9. Liu J, Li D, Cao L, Wang Z, Li Y, Liu H, Chen G. Elevated preoperative plasma fibrinogen level is an independent predictor of malignancy and advanced stage disease in patients with bladder urothelial tumors. International Journal of Surgery. 2016; 36: 249-54.

10. Lee H, Lee SE, Byun SS, Kim HH, Kwak C, Hong SK. Preoperative plasma fibrinogen level as a significant prognostic factor in patients with localized renal cell carcinoma after surgical treatment. Medicine (United States). 2016; 95.

11. Erdem S, Amasyali AS, Aytac O, Onem K, Issever H, Sanli O. Increased preoperative levels of plasma fibrinogen and $\mathrm{d}$ dimer in patients with renal cell carcinoma is associated with poor survival and adverse tumor characteristics. Urologic Oncology: Seminars and Original Investigations. 2014; 32: 1031-40.

12. Perisanidis C, Psyrri A, Cohen EE, Engelmann J, Heinze G, Perisanidis B, Stift A, Filipits M, Kornek G, Nkenke E. Prognostic role of pretreatment plasma fibrinogen in patients with solid tumors: A systematic review and meta-analysis. Cancer Treat Rev. 2015; 41: 960-70.

13. Tian $Y$, Hong M, Jing S, Liu X, Wang H, Wang X, Kaushik D, Rodriguez R, Wang Z. Clinical and Prognostic Effect of Plasma Fibrinogen in Renal Cell Carcinoma: A Meta-Analysis. BioMed Research International. 2017; 2017.

14. Liu J, Li D, Cao L, Wang Z, Li Y, Liu H, Chen G. Elevated preoperative plasma fibrinogen level is an independent predictor of malignancy and advanced stage disease in patients with bladder urothelial tumors. Int J Surg. 2016; 36: 249-54.

15. Ma C, Lu B, Diao C, Zhao K, Wang X, Ma B, Lu B, Sun E. Preoperative neutrophil-lymphocyte ratio and fibrinogen level in patients distinguish between muscle-invasive bladder cancer and non-muscle-invasive bladder cancer. OncoTargets and Therapy. 2016; 9: 4917-22.

16. Sheng L, Luo M, Sun X, Lin N, Mao W, Su D. Serum fibrinogen is an independent prognostic factor in operable nonsmall cell lung cancer. Int J Cancer. 2013; 133: 2720-5.

17. Man YN, Wang YN, Hao J, Liu X, Liu C, Zhu C, Wu XZ. Pretreatment plasma D-dimer, fibrinogen, and platelet levels significantly impact prognosis in patients with epithelial ovarian cancer independently of venous thromboembolism. Int J Gynecol Cancer. 2015; 25: 24-32.

18. Zhao K, Deng H, Qin Y, Liao W, Liang W. Prognostic significance of pretreatment plasma fibrinogen and platelet levels in patients with early-stage cervical cancer. Gynecol Obstet Invest. 2015; 79: 25-33.

19. Kinoshita A, Onoda H, Imai N, Iwaku A, Oishi M, Tanaka K, Fushiya N, Koike K, Nishino H, Matsushima M, Tajiri H. Elevated plasma fibrinogen levels are associated with a poor prognosis in patients with hepatocellular carcinoma. Oncology. 2013; 85: 269-77.

20. Qi Q, Geng Y, Sun M, Chen H, Wang P, Chen Z. Hyperfibrinogen Is Associated With the Systemic Inflammatory Response and Predicts Poor Prognosis in Advanced Pancreatic Cancer. Pancreas. 2015; 44: 977-82.

21. Son HJ, Park JW, Chang HJ, Kim DY, Kim BC, Kim SY, Park SC, Choi HS, Oh $\mathrm{JH}$. Preoperative plasma hyperfibrinogenemia is predictive of poor prognosis in patients with nonmetastatic colon cancer. Ann Surg Oncol. 2013; 20: 2908-13.

22. Lu K, Zhu Y, Sheng L, Liu L, Shen L, Wei Q. Serum fibrinogen level predicts the therapeutic response and prognosis in patients with locally advanced rectal cancer. Hepatogastroenterology. 2011; 58: 1507-10.

23. Rybarczyk BJ, Simpson-Haidaris PJ. Fibrinogen assembly, secretion, and deposition into extracellular matrix by MCF-7 human breast carcinoma cells. Cancer Res. 2000; 60: 2033-9.

24. Sahni A, Odrljin T, Francis CW. Binding of basic fibroblast growth factor to fibrinogen and fibrin. J Biol Chem. 1998; 273: 7554-9.

25. Sahni A, Francis CW. Vascular endothelial growth factor binds to fibrinogen and fibrin and stimulates endothelial cell proliferation. Blood. 2000; 96: $3772-8$

26. Staton CA, Brown NJ, Lewis CE. The role of fibrinogen and related fragments in tumour angiogenesis and metastasis. Expert Opin Biol Ther. 2003; 3: 1105-20.

27. Palumbo JS, Talmage KE, Liu H, La Jeunesse CM, Witte DP, Degen JL. Plasminogen supports tumor growth through a fibrinogen-dependent mechanism linked to vascular patency. Blood. 2003; 102: 2819-27.

28. Palumbo JS, Potter JM, Kaplan LS, Talmage K, Jackson DG, Degen JL. Spontaneous hematogenous and lymphatic metastasis, but not primary tumor growth or angiogenesis, is diminished in fibrinogen-deficient mice. Cancer Res. 2002; 62: 6966-72.

29. Palumbo JS, Kombrinck KW, Drew AF, Grimes TS, Kiser JH, Degen JL, Bugge TH. Fibrinogen is an important determinant of the metastatic potential of circulating tumor cells. Blood. 2000; 96: 3302-9. 
30. Zheng S, Shen J, Jiao Y, Liu Y, Zhang C, Wei M, Hao S, Zeng X. Platelets and fibrinogen facilitate each other in protecting tumor cells from natural killer cytotoxicity. Cancer Sci. 2009; 100: 859-65.

31. Zhou L, Cai X, Liu Q, Jian ZY, Li H, Wang KJ. Prognostic Role of C-Reactive Protein In Urological Cancers: A Meta-Analysis. Sci Rep. 2015; 5: 12733.

32. Wang PF, Song HW, Cai HQ, Kong LW, Yao K, Jiang T, et al. Preoperative inflammation markers and IDH mutation status predict glioblastoma patient survival. Oncotarget. 2017; 8: 50117-23.

33. Esumi N, Fan D, Fidler IJ. Inhibition of murine melanoma experimental metastasis by recombinant desulfatohirudin, a highly specific thrombin inhibitor. Cancer Res. 1991; 51: 4549-56.

34. Wang Y, Yin W, Wang Z, Huang J, Pan J, Zhu Y, Xu F, Shao X, Sha J, Cai Y, Liu Q, Dong B, Xue $W$, et al. Pretreatment plasma fibrinogen as an independent prognostic indicator of prostate cancer patients treated with androgen deprivation therapy. Prostate Cancer and Prostatic Diseases. 2016; 19: 209-15.

35. Pichler M, Hutterer GC, Stojakovic T, Mannweiler S, Pummer K, Zigeuner R. High plasma fibrinogen level represents an independent negative prognostic factor regarding cancer-specific, metastasis-free, as well as overall survival in a European cohort of non-metastatic renal cell carcinoma patients. British Journal of Cancer. 2013; 109: 1123-9.

36. Niedworok C, Dorrenhaus B, Vom Dorp F, Piotrowski JA, Tschirdewahn S, Szarvas T, Rubben H, Schenck M. Renal cell carcinoma and tumour thrombus in the inferior vena cava: clinical outcome of 98 consecutive patients and the prognostic value of preoperative parameters. World J Urol. 2015; 33: 1541-52.

37. Sasaki T, Onishi T. Pretherapeutic plasma fibrinogen level is an independent survival predictor in renal cell carcinoma. Oncology Research and Treatment. 2015; 38: 374-8

38. Obata J, Tanaka N, Mizuno R, Kanao K, Mikami S, Matsumoto K, Kosaka T, Kikuchi E, Jinzaki M, Oya M. Plasma fibrinogen level: an independent prognostic factor for disease-free survival and cancer-specific survival in patients with localised renal cell carcinoma. BJU International. 2016; 118: 598-603

39. Peng D, He ZS, Li XS, Tang Q, Zhang L, Yang KW, Yu XT, Zhang CJ, Zhou LQ. A novel predictor of survival with renal cell carcinoma after nephrectomy. Journal of Endourology. 2017; 31: 397-404

40. Pichler M, Dalpiaz O, Ehrlich GC, Stojakovic T, Martin Hernandez JM, Mannweiler S, Pummer K, Zigeuner R, Hutterer GC. Validation of the preoperative plasma fibrinogen level as a prognostic factor in a European cohort of patients with localized upper tract urothelial carcinoma. J Urol. 2014; 191: 920-5.

41. Zhang B, Song Y, Jin J, Zhou LQ, He ZS, Shen C, He Q, Li J, Liu LB, Wang C, Chen XY, Fan Y, Hu S, et al. Preoperative plasma fibrinogen level represents an independent prognostic factor in a Chinese cohort of patients with upper tract urothelial carcinoma. PLoS ONE. 2016; 11(3): e0150193.

42. Huang J, Yuan Y, Wang Y, Zhang J, Kong W, Chen H, Chen Y, Huang Y. Prognostic value of preoperative plasma fibrinogen level and platelet-to-lymphocyte ratio (F-PLR) in patients with localized upper tract urothelial carcinoma. Oncotarget. 2016. 8:36761-36771. 